Please quote as: Fähling, J.; Leimeister, J. M.; Yetton, P. \& Krcmar, H. (2009): Managing an IT carve-out at a multi-national enterprise. In: Proceedings of the 17th European Conference on Information Systems (ECIS), Verona, Italy. 


\title{
MANAGING AN IT CARVE-OUT AT A MULTI-NATIONAL ENTERPRISE TEACHING CASE DESCRIPTION
}

Fähling, Jens, Technische Universität München, Chair for Information Systems,

Boltzmannstr. 3, 85748 Garching b. München, Germany, faehling@ in.tum.de

Leimeister, Marco, Universität Kassel, Fachbereich Wirtschaftsinformatik, Nora-Platiel-Str. 4, 34127 Kassel, Germany, leimeister@ uni-kassel.de

Yetton, Philip, University of NSW, Australian School of Business Building, Kensington, NSW 3052, Australia, phily@agsm.edu.au

Krcmar, Helmut, Technische Universität München, Chair for Information Systems,

Boltzmannstr. 3, 85748 Garching b. München, Germany, krcmar@in.tum.de

\begin{abstract}
Mergers, acquisitions and divestments, including the carve-outs of business units or parts of them, are standard strategies used by multi-divisional organizations to adjust their business portfolios. Carveout projects are critically dependent on their management of IT. Systems, which have been integrated in order to deliver seamless and efficient IT operations, must now be pulled apart under demanding time and compliance constraints. In 2007, Delta IT Consulting (DIC), one of France's biggest ITservice provider, sold one of its three service provider divisions, IT Product Services (IPS). This division employed about 3,500 employees in 20 countries and previously generated 0.7 billion of DIC's 3.8 billion euro revenues. DIC itself is a division of Delta Corporation - a French high-tech company and leading player in a wide array of businesses, industries and countries around the world. This teaching case challenges the reader to analyse and manage the IT carve-out as a critical component within the divestment project. The case includes insights into strategic and organizational challenges of planning and managing an IT carve-out project.
\end{abstract}

Keywords: teaching case, IT carve-out, IT project management, IT management.

[The names, dates and numbers have been changed for business in confidence reasons.] 


\section{INTRODUCTION}

On December 4th, 2007, Delta IT Consulting (DIC) ${ }^{1}$ entered into a contract to sell its IT Product Services (IPS) division as part of "Organize4Profit", its corporate organization-wide restructuring program $^{2}$. This strategic business unit (SBU), which represented 0.7 billion of the IT services unit's 3.8 billion euro revenues, was one of three SBUs in DIC. A new CEO, Thomas Hutton, had been appointed in October with a mandate from Jean Claude, the Chairman of Delta Corporation, to restructure DIC, consolidating its sites in France from 48 to 21. The media coverage was intense.

IT was one of ten work streams in the carve-out project. All members of the IT carve-out team (IT-cut) were appointed at short notice. Nobody in the team had any experience of working on a carve-out project. However, everyone agreed that the following months would be extremely hard and timeconsuming. Team members had to sign non-disclosure agreements, which were not part of their regular contracts. These were not only to guarantee confidentiality for the negotiations but also to ensure compliance with anti-trust regulations. Some team members wondered if they would have a job when the carve-out was signed off.

"We have to hurry," said Alain Croix, Chief Information Officer at Delta IT Consulting (DIC) in his first communication with IT-cut, "Time is short. The sale closes on April 1 next year. It is only three and a half months to the hand-over."

This case study examines the strategic and organizational challenges of planning and managing an IT carve-out project. Acquisitions and divestments are critical strategic decisions in global organizations such as Delta Group, with major political and reputation consequences, and significant impacts on their bottom lines. For example, the cost of an IT carve-out is frequently significant relative to the other sale costs. More importantly, IT carve-outs must meet deadlines and functionality imposed by the sale contract or incur substantial penalties. Therefore, the success of a divestment, such as the one made here by DIC, was critically dependent on IT-cut's performance.

\subsection{Business background/ context}

Delta Group is a major global organization, operating in 160 countries. In 2007, it employed 372,000 people worldwide, generating revenues of more than 71 billion euro, with a net income of over 2.4 billion euro.

DIC was part of the Digital Processing and Transmitting business area, offering a broad portfolio of multi-vendor IT solutions and services for the private and public sector. With 10,000 customers, DIC was one of the world's leading providers of IT services, generating revenues in 2007 of 3.8 billion euro. Its portfolio contained a range of services from consulting and system integration to the management and operation of IT infrastructure and entire business processes.

DIC was divided into three business divisions. The IT Solution Services division covered the first phase in the IT lifecycle. This included consulting services and the definition of customer solutions, including SAP, system integration, and IT and process consulting. The IT Operations Services division covered the second phase in the IT lifecycle. This included both the outsourcing of IT intensive business processes, including HR and financial services, and the management of data centres, desktop environments, LAN/WAN and call centres. The IT Product Services division (IPS) covered the third phase in the IT lifecycle, specifically maintenance and infrastructure services. IPS delivered platform-

\footnotetext{
${ }^{1}$ In 2007, DIC was one of five core 'business areas' in Delta Group, a global corporation in electronics, engineering, energy and healthcare.

${ }^{2}$ In April 2007, Delta embarked on a major restructuring project Organise4Profit.
} 
independent IT infrastructure services and solutions that addressed customers' high availability, consolidation, migration and lifecycle management requirements, supporting a range of third-party platforms.

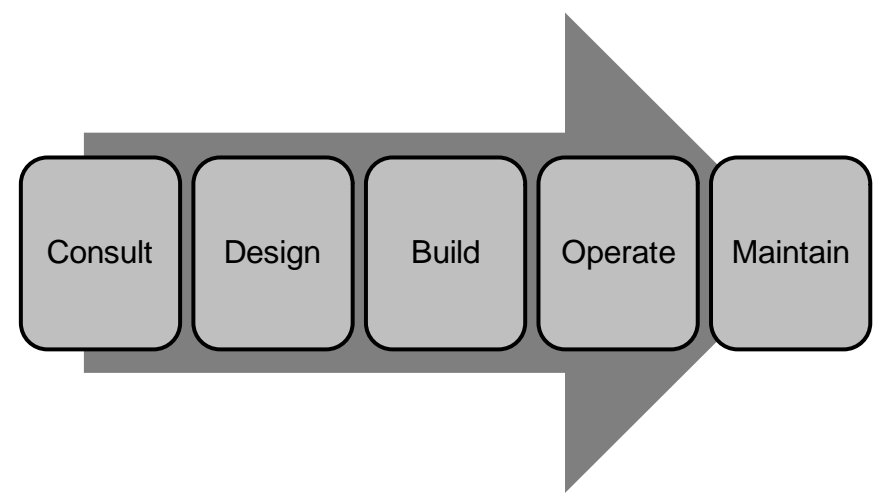

Figure 1: DIC Business Portfolio

In 2007, DIC was expecting to lose $109 \mathrm{~m}$ euro, down from a profit the previous year of $40 \mathrm{~m}$ euro. In April 2007 Delta Group had embarked on a major restructuring project, Organise4Profit. As part of that initiative, Delta Group was looking for a solution for this challenged SBU.

\section{THE CARVE-OUT}

Starting in September 2007, there had been rumors in the media about major changes at Delta, including Delta IT Consulting (DIC), to help the Chairman achieve his target of 5\%-6\% profit for all SBUs by mid-2009.

Off the record, Delta managers had admitted that DIC had too many contracts that were not profitable. This had led to major write-downs. The French business press reported early in October that all of DIC would be sold.

In November, the press speculated that Siemens had made an offer but this was denied. There was further speculation about negotiations with other companies from the USA and Germany, including Gedas, the IT service provider at Volkswagen, and International Computer Services (ICS), a 50-50 joint venture between Delta and International Computer Industries ${ }^{3}$.

Finally, on December 4, it was announced that Delta was selling the IPS business to ICS. IPS by itself was one of the largest IT service company worldwide, employing 2,300 people in 17 countries and with a global network of 60,000 service partners and system integrators delivering services in 140 countries. Selling to ICS was logical because IPS's customers were also customers of ICS. Selling IPS to a competitor would have been a serious threat to ICS, with the new owner acquiring both major service contracts and access to valuable insights into ICS technology.

The importance of the IPS acquisition was highlighted in the ICS Annual Report 2008, page 77:

"The Services Division of ICS commenced business under ICS management on April 1, 2008. IPS and ICS are a perfect match. This is clearly reflected in the smooth integration. Ninety four percent of all customer contracts and 86 percent of former IPS employees transferred to the new Services Division on April 1. This is a major strategic

\footnotetext{
${ }^{3}$ ICS delivers innovative, high quality IT products, infrastructure solutions and services to corporations, SMEs, and private users in all key markets across Europe, the Middle East and Africa. ICS's offerings range from the smallest handhelds, through personal computing systems, to fully integrated enterprise-class infrastructure solutions. ICS complements this offering with the expertise of leading technology, software and service partners.
} 
acquisition for us, building on our vision of a full-service, customer-driven organisation. The extended service portfolio enables us to compete more effectively against the other major players in this sector. The Services Division will operate as a separate subsidiary."

On December 20, 2007, Delta and ICS signed a contract for ICS to buy IPS.

\section{THE IT CHALLENGE}

Confidential negotiations between Delta and ICS had begun in early October 2007, covering strategic aspects, including customer transfer, market expansion and business portfolio development. The Project Manager of the carve-out project was not part of the negotiation. Indeed, nobody from the carve-out team, let alone any member of IT-cut, had attended any of those negotiations. As a consequence, the contract covered very few aspects of the IT handover.

The overall carve-out project structure consisted of 10 work streams, of which IT was one. For example, the Human Resources work stream was responsible for all personnel issues, including negotiations about which employees would move to ICS. The legal work stream was responsible for conforming to the relevant regulations in the affected countries. Another work stream was responsible for the transfer of real estate. With many unique and unfamiliar tasks, the project team also hired a large number of consultants to support the work streams.

The IT work stream's tasks were divided into IT infrastructure and IT applications. IT infrastructure covered all network issues, including rules for ICS to access the DIC's IT systems during the transition phase. Telephone, fax, email, file services, print, desktop environments, back office systems and security were also part of the IT infrastructure domain. In addition, Internet and intranet systems had to move to ICS. Finally, all services that supported the data centers were migrated.

Within Delta, some local IT applications were under the control of regional business units, while core systems were centralized. Central applications were mandated for all countries, while local applications were approved only for a business unit from a specific country. The IT system for corporate group control, reporting and financials was an example of a central application. While these centrally controlled applications were immediately salient and visible to IT-cut, local applications were not well documented and were hard to track.

Because of the difficulty in identifying the relevant local applications, ensuring their timely migration to ICS was a major challenge. Each IT application had to be classified as a Delta-wide, DIC-wide or IPS-specific application. A pre-requisite for the classification project was an agreed process for the assessment of each application.

For example, consider the spare parts ordering system and the maintenance management system. While the former was used for the order and delivery of spare parts, it also triggered the billing process. The latter scheduled maintenance calls. Both systems were IPS specific. One advantage of IPS applications was their independence from IT Operations Services and IT Solution Services, the two other divisions in DIC. The datasets for these systems belonged specifically to IPS and there was no need to identify, separate and carve-out the relevant data. In contrast, the separation of shared DIC or Delta-wide applications was challenging. 


\begin{tabular}{|c|c|c|c|c|}
\hline & & \multicolumn{3}{|c|}{ Organization Structure } \\
\cline { 2 - 5 } Locus of \\
Control & Local & $\begin{array}{c}\text { IPS-wide local } \\
\text { applications: } \\
\text { e.g. sales system }\end{array}$ & $\begin{array}{c}\text { DIC } \\
\text { DIC-wide local } \\
\text { applications: } \\
\text { e.g. charging system }\end{array}$ & $\begin{array}{c}\text { Delta-wide local } \\
\text { applications: } \\
\text { e.g. accounting } \\
\text { system }\end{array}$ \\
\cline { 2 - 5 } & Central & $\begin{array}{c}\text { IPS-wide central } \\
\text { applications: } \\
\text { e.g. spare part ordering }\end{array}$ & $\begin{array}{c}\text { DIC-wide central } \\
\text { applications: } \\
\text { e.g. scheduling and } \\
\text { billing of expenses for } \\
\text { mobile technicians }\end{array}$ & $\begin{array}{c}\text { Delta-wide central } \\
\text { applications: } \\
\text { e.g. mailing and } \\
\text { groupware system, } \\
\text { business warehouse }\end{array}$ \\
\hline
\end{tabular}

\section{Table 1: Six types of IT applications at Delta}

The scheduling and billing systems for mobile technicians was an example of a DIC-wide application. This system was used by all DIC mobile technicians regardless of whether they worked for IPS or another SBU in DIC. In this case, IPS-relevant data had to be identified and carved out. Unlike the simple, direct transfer of an IPS-wide application to ICS, the transfer of a DIC-wide application was complex. The first decision to be made was whether to transfer the applications and data to ICS, or to separate the data and integrate it into an existing, similar system at ICS. A secondary decision was whether the historical data was important to ICS or whether ICS could be given access to the data by Delta via a Transition Service Agreement (TSA) for a specified period.

Delta-wide applications included, for example, mailing, groupware systems, and business warehouse and business intelligence solutions. Mailing and groupware systems were based on Microsoft technology, while financial and controlling systems, and the business warehouse and intelligence solutions were based on SAP technology. Mailing data for the affected IPS employees could have been carved out easily because each employee had an encapsulated mailbox. However, any employee in IPS was able to store documents and post comments to the Delta groupware platform. Therefore, it was difficult to identify and separate all relevant IPS employee documents and comments in order to both transfer them to ICS's groupware system and delete them from Delta' groupware system.

This was also the case for other Delta systems, including business warehouse and business intelligence solutions. Delta had invested heavily to harmonize the reporting structure across all business areas and regional business units. To do that, Delta had developed a standardized architecture for the business warehouse landscape in all regional business units. With integrated templates for the regional business units, Delta was able to consolidate quickly and easily across its warehouses around the world. Not surprisingly, these templates were not useful to ICS because it had implemented a different reporting system. The contract partners had to develop solutions to break such Delta-wide applications apart and to transfer them to ICS's existing IT landscape.

Fortunately, both Delta and ICS used Microsoft technology for mailing, office and collaboration, and SAP for their financial and administrative backbones. This meant that there was a relatively high degree of compatibility between IPS and ICS systems. Unfortunately, that was the exception, and major differences between the IT systems of IPS and ICS were found everywhere. The problems were always in the detail. For example, there were differences in the desktop standard client. Although both partners used Microsoft Windows, the installed desktop standard client of IPS could not be used in the ICS environment. As a consequence, all desktop PCs transferred from IPS to ICS had to have the ICS desktop standard client installed.

IT-cut had to decide how to handle each application separately, with particular attention to the shared DIC-wide and Delta-wide applications. 
Marcel Dupuis, leader of IT-cut, identified three critical IT challenges for IT-cut.

"The first is that some IT systems at IPS are hosted on the Delta IT platform and are highly integrated with other Delta IT systems. So, we have to work out how to identify the relevant IT systems and how to cut them out of our overall IT platform. But remember, while some IT systems are IPS-specific and are managed by IPS, they may also be used by other divisions."

The second was:

"The complexity of the carve-out project itself. IT is only one work stream, although an important one, of this carve-out project. As one of the first steps, we will define the interfaces between our IT work stream and the other work streams (including Human Resources, Customer Contracts and Legal Issues) to ensure a good information flow."

The third was the global coverage:

"I also anticipate changes in the number of countries to be affected by the carve-out, due to legal or strategic issues. IT is not organized centrally. Regional departments have certain authorities and power over IT decisions. This existence of local infrastructure and applications significantly increases the complexity of the IT carve-out project"

\section{CARVE-OUT PROCESS}

Figure 1 documents the steps to be followed in a typical IT carve-out project. The overall process is divided into four phases. These are separated by specific milestones. The first phase, "Pre-Signing", clarifies and agrees all aspects concerning the contract. This includes the dates for the Closing milestone, the Transition phase and the Cutting milestone. In addition, the contract partners agree upon the distribution of costs for the overall carve-out project. This phase ends with the milestone "Signing" of the contract between the buyer and seller, finalizing the legal framework for the carveout.

In France, without specific approval from the anti-trust agency, the seller's project integration teams are not allowed to talk to the buyer about the carve-out. In this case, that approval was not expected to be given before the end of January 2008. Therefore, IT-cut had to plan and begin the project without communicating with ICS.

As part of the contract, it was agreed that ICS would have access to the IPS's IT systems for six more months after Signing. Delta/DIC would provide the IT support and access for ICS during that period.

The second phase, "Pre-Closing", establishes a working project management structure and creates the project management office. The IT carve-out team began its work stream with the analysis of networks and IT basic services. The relevant IT applications were identified, evaluated and prioritized for the IT carve-out.

The second phase ends with the "Closing" milestone. By then, all relevant IT systems had to be separated from DIC's IT systems and exclusively under the control of ICS, guaranteeing its independence from DIC. This included separating the IT infrastructure, including email accounts, networks and telecommunication services. 


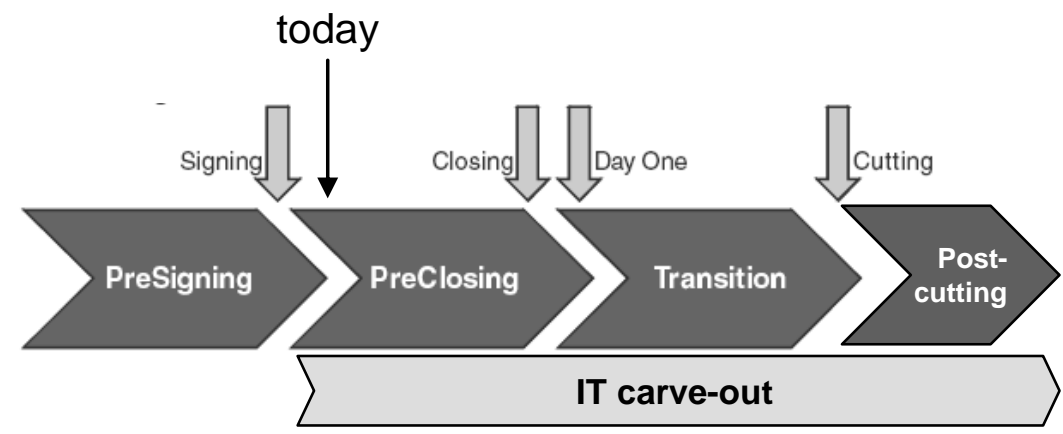

Figure 2: Carve-out phases

The third phase, "Transition", commences the day after Closing. On "Day One", ICS required access to historical financial data and to have the capacity to manage its business within its own IT systems. Recognizing time constraints, and the time needed to carve out and integrate all relevant IT systems into the ICS's IT infrastructure, DIC created a copy of the relevant IT systems, deleting all the data that was not included in the contract. During the remainder of the transition phase, DIC gave ICS access to DIC's IT systems. This required the development of strict rules covering the access to the DIC's network by ICS. This is terminated at the "Cutting" milestone. After the "Cutting" milestone, fourth phase named "Post-cutting" - while ICS still has access to DIC's network, ICS had established its own network and the network connection at DIC was physically decommissioned.

\section{GETTING GOING}

With no experience of an IT carve-out, the members of IT-cut have many questions for Marcel Dupuis. One of the team members asks: "Why do we have to do the IT carve-out in two steps? Why must we first duplicate all systems to fulfill the contract in time and then carve out all affected systems of our IT landscape afterwards in order to transfer them to ICS? Can't we carve out the relevant IT systems until Closing?" Marcel stops him there and replies: "No, the task is too complex. At this time, we have no idea how many local IT systems are running in the affected countries. And the regional companies in those countries have strong power bases at Delta Head Office. It will not be easy to get all the relevant information quickly. We have to ensure that the regional companies are working with and not against us."

Paul Alexander, a specialist in IT contracting, asks: "And how can we warrant this for ICS?" "With the help of Transition Services Agreements (TSA)", replies Alain. "TSAs govern access by business partners to our network. Therefore, we need strict rules to manage the carve-out firewall."

"But, we have corporate guidelines for approving IT systems. According to those guidelines, we should be able to make a good guess about the affected IT systems in each country," comments Carol Williams, who is specialist from organizational affairs. "You are right," says Alain. "But guidelines are guidelines and not laws. Unfortunately, we are not able to monitor and control all regional business units and their IT portfolio. A certain freedom of choice is necessary to run effective regional business units. In addition, the guidelines are frequently only applied to Delta-wide global applications, for example, the e-mail and groupware standards. In the best case, a regional business unit has its own documentation system, but many of the regional business units have no documentation. Therefore, the identification of all affected local applications is one of our biggest challenges. We need to appoint a dedicated person to coordinate across the regional business units. This will synchronize our carve-out activities and approaches." 
"When we have identified all affected IT applications, would it be possible for us to simply separate those systems out of the existing IPS IT landscape?" asked Paul. "That is difficult, because the IT systems are tightly integrated with and connected to each other. But we could try this approach for IPS-wide applications," answers Alain.

Carol offers another solution: "Could we copy and duplicate all affected systems and give them to ICS?" All the IT-cut members pause for a moment and think over this suggestion. Finally, Ernesto, a specialist on IT infrastructure, answers: "That approach sounds interesting. Unfortunately, it would be extremely expensive for us. And, in the end, it is likely that ICS would not want to have all of our IT systems, but only want to integrate the data into their existing systems." Alain comments:

"Additionally, almost every IT system is connected to another one. This means, that data is distributed all over the IT landscape and interlinked. In the worst case, we would have to duplicate our whole IT landscape, which is not realistic".

"Ok, but then we could go another way. We could build up all relevant IT systems for IPS from scratch and only give over the datasets," Paul suggests. Ernesto counters: "Then, what would we do with the existing contracts and depreciation schedules? What will happen to the old IPS systems that we do not need anymore?"

A lot of work is waiting for Alain Dupuis and his team in the next few months. It is clear, that this is not a simple task. The IT carve-out will end on April 1, which is only three and a half months away. The members of IT-cut are beginning to realize that an IT carve-out is more than just carve out IT. It is time to start.

\section{CASE QUESTIONS AND ISSUES}

1. Position the IT workstream within the overall project organization of the carve-out. What are the critical roles and competences required within the IT workstream?

2. Identify the main tasks for the IT carve-out and combine them within a project plan. Use milestones to structure the plan. Begin with the basic carve-out process model and extend as needed.

3. How can IT-cut establish transparency for the existing infrastructure and applications? Develop a data collection template.

4. How should IT-cut prioritize applications/systems for transfer? Develop a prioritization logic based on your data collection template developed in response to issue 3 .

5. Develop a basic reporting tool and a management dashboard for the work stream project managers. 